\title{
PENGARUH STORE LAYOUT DAN ATMOSPHERE TERHADAP SHOPPING INTENTION ZALORA ONLINE STORE
}

\author{
Sany Surya \\ Dudi Anandya (samkidud@gmail.com) \\ Christina Rahardja Honantha (christina_r@staff.ubaya.ac.id) \\ Fakultas Bisnis dan Ekonomika Universitas Surabaya
}

\begin{abstract}
This study aims to know and analyze the influence of layout design and atmosphere on purchase intention trough emotional arousal and attitude toward the website. This research using SPSS 1.6 and Lisrel 8.7 software. Data collected directly from respondents who meet the specified characteristics of the population by distributing questionnaires. The samples used in this study was 150 respondents. The results of this study showed the influence of layout design on emotional arousal and attitude toward the website, the influence of atmosphere on emotional arousal, the influence of emotional arousal on attitude toward the website, the influence of emotional arousal on purchase intention, the influence of attitude toward the website on purchase intention, while the influence of atmosphere on emotional arousal, and the influence of emotional arousal on purchase intention of Zalora online store are rejected.
\end{abstract}

Keywords: Layout design, Atmosphere, Emotional Arousal, Attitude toward the website, Purchase intention

\begin{abstract}
Abstrak
Penelitian ini bertujuan untuk mengetahui dan menganalisis pengaruh desain tata letak dan atmosfir terhadap minat beli melalui emotional arrousal dan sikap terhadap website. Pengolahan data menggunakan software SPSS 18 dan Lisrel 8.7 dengan analisis structural equation modeling (SEM). Data dikumpulkan dengan menyebarkan kuesioner kepada responden yang telah memenuhi karakteristik populasi yang ditentukan. Jumlah sampel penelitian ini 150 responden. Hasil penelitian menunjukkan terdapat pengaruh desain tata letak terhadap emotional arrousal dan sikap terhadap website, pengaruh atmosfir terhadap emotional arousal, pengaruh emotional arousal terhadap sikap terhadap website, pengaruh emotional arousal terhadap minat beli. Tidak terdapat pengaruh atmosfir terhadap sikap terhadap website dan pengaruh emotional arousal terhadap minat beli pada Zalora online store.
\end{abstract}

Kata kunci: desain tata letak, atmosfir, emotional arousal, sikap terhadap website, minat beli 


\section{Sany Surya \\ Dudi Anandya \\ Christina Rahardja Honantha}

\section{PENDAHULUAN}

Seiring dengan pertumbuhan teknologi yang sangat pesat, persaingan di bidang usaha menjadi lebih sengit bila dibandingkan dengan sebelumnya. Dengan adanya perkembangan teknologi, perusahaan tidak lagi harus membuat toko fisik untuk memulai usahanya, sudah banyak toko- toko yang menawarkan barang yang dijual secara online dengan harga yang lebih terjangkau dan dengan kualitas yang cukup bersaing bagi konsumen. Toko online dapat menjadi salah satu keunggulan karena dengan adanya toko online, perusahaan mampu mendapatkan market share yang lebih luas tanpa mengelvarkan biaya yang besar.

Didukung dengan pesatnya pertumbuhan pengguna internet di Indonesia dimana "pada akhir tahun 2013 berdasarkan survei yang dilakukan oleh Badan Pusat Statistik (BPS) bekerjasama dengan Asosiasi Penyelenggara Jasa Internet Indonesia (APJII) mencapai 71,19 juta orang" (http://harianti.com). Tercatat pada tahun 2013 melalui survei yang dilakukan Mastercard Worldwide terdapat 36 juta orang yang aktif melakukan bisnis online. Agar mampu bersaing di bisnis ini para pengusaha harus mempunyai tampilan website yang menarik serta mempunyai produk yang berbagai macam.

"Terdapat enam pelaku industri e-commerce yang saat ini mendominasi pasar online Indonesia yaitu Tokopedia.com, OLX.com, Bhinneka.com, Berniaga.com, Lazada, dan Zalora" (http://www.tekno.liputan6.com). Zalora Indonesia merupakan toko online yang mengkhususkan diri pada kebutuhan fashion. Zalora menawarkan beberapa produk dari beragam brand terkenal, baik produk lokal maupun internasional. Zalora Indonesia didirikan pada tahun 2012 lalu yang merupakan satu dari cabang situs belanja online terbesar Eropa bernama Zalando yang merupakan salah satu anak perusahaan dari Rocket Internet yang juga merupakan perusahaan induk dari Lazada. Selain online store tersebut terdapat online store lain yang khusus menjual produk fashion seperti "BerryBenka yang memiliki sekitar 300400 transaksi per harinya" (http://merdeka.com).

Zalora adalah salah satu perusahaan e-commerce yang paling cepat berkembang di Asia Tenggara termasuk di Indonesia, serta saat ini sendiri dapat dikatakan memiliki prospek cerah, dimana "aplikasi yang dimiliki Zalora menjadi \# 1 lifestyle app untuk semua negara dan top overall app untuk Singapore, Malaysia, dan Vietnam" (http://swa.co.id/). Desain website yang ditampilkan oleh Zalora mencerminkan halaman yang sangat informatif mengenai detail produk, pilihan motif, dan waktu pengiriman. Secara keseluruhan website e-commerce Zalora.co.id sudah mencerminkan website belanja online yang sangat bagus dengan peringkat rating google tertinggi untuk kategori pencarian menandakan bahwa website ini juga membuktikan bahwa developer sangat memperhatikan unsur SEO (Search Engine Optimation).

\section{KAJIAN TEORITIS, PENGEMBANGAN HIPOTESIS DAN MODEL PENELITIAN}

\section{THE STIMULUS- ORGANISM- RESPONSE (S-O-R) FRAMEWORK}

Menurut Wann, Chia, Chen, dan Hong (2014), terdapat tahap pertama adalah Stimulus(S), yang meliputi desain layout toko dan atmosfer. Tahap kedua adalah Organism (O), yang mencakup dua faktor utama dari sebuah website yaitu emotional arousal dan sikap terhadap website. Tahap terakhir yaitu Response (R), yang akan menjelaskan minat beli konsumen setelah mengunjungi suatu website.

\section{Layout Design}

Layout merupakan susunan dan letak dari berbagai kelengkapan kelengkapan yang dibutuhkan oleh toko tersebut agar terkesan rapi dan menarik untuk dilihat sehingga para pengunjung tidak merasa bingung ketika berada di dalam toko tersebut. Menurut Wann et 
al., (2014) Layout design adalah tatanan konten produk dan gambar di dalam suatu website. Dalam studi ini, layout design didefinisikan sebagai penataan konten dari informasi produk dan gambar yang ada di dalam website tersebut.

\begin{abstract}
Atmosphere
Menurut Wann et al., (2014) Atmosphere didefinisikan sebagai warna yang digunakan dalam website yang dapat mempengaruhi emosi dari konsumen. Dalam studi ini atmosfer didefinisikan sebagai warna yang digunakan dalam suatu website.
\end{abstract}

\title{
ORGANISM
}

\section{Emotional Arousal}

Emosi konsumen biasanya digunakan sebagai salah satu variabel dalam studi perilaku konsumen. Menurut Wann et al, (2014) Emotional arousal terdiri dari dua komponen yaitu pleasure dan arousal. Pleasure didefinisikan sebagai derajat perasaan dimana konsumen merasa senang, bahagia dan gembira, sedangkan arousal didefiniskan sebagai derajat perasaan dimana konsumen merasa tertarik, waspada dan aktif. Sehingga dari dua definisi diatas emotional arousal adalah derajat perasaan dimana seseorang merasa senang, bahagia, gembira, merasa tertarik, waspada dan aktif.

\section{Attitude Toward the Website}

Sikap merupakan salah satu evaluasi yang menyeluruh dan memungkinkan seseorang untuk merespon dengan perasaan suka atau tidak suka terhadap objek yang dinilai. Wann et al, (2014) mendefinisikan sikap terhadap website sebagai evaluasi secara emosional yang timbul setalah konsumen mengunjungi website.

\section{RESPONSE}

\section{Purchase Intention}

Menurut Soderlund dan Ohman (2005), ada tiga jenis konstruk minat membeli yaitu : (1) Intensi sebagai harapan, (2) Intensi atau minat sebagai rencana, dan (3) Intensi atau minat sebagai keinginan. Menurut Wann et al, (2014) purchase intention adalah probabilitas dan niat konsumen untuk membeli barang tertentu.

\section{Online Retailing and Website Design}

Retail online adalah sektor yang dinamis, kompleks, dan kompetitif dimana suatu perusahaan menyediakan berbagai macam produk dan layanan jasa kepada konsumen secara online melalui internet (Kilic dan Senol, 2010). Menurut Heinemann dan Schwarzl (2010;p.215) keunggulan dari penggunaan retail online adalah : meningkatkan konsumen potensial, pangsa pasar yang lebih besar, biaya pemasaran yang efektif, penyebaran risiko, fleksibilitas, loyalitas konsumen, meningkatkan image, dan brand revitalisation.

Menurut Eroglu, Machleit, dan Davis (2003) dalam Wan et al., (2013) atmosfer dari suatu website, meliputi desain layout dari website tersebut, yang dapat mempengaruhi kesenangan dan gairah dari pengunjung website.

H1 : Desain layout dari suatu website akan memiliki hubungan positif terhadap emotional arousal konsumen online shop.

Toko online memiliki kemiripan dengan toko tradisional pada umumnya, namun toko online tidak memiliki beberapa dimensi yang ada pada toko fisik (contoh : temperatur dan aroma) dan tidak adanya pertemuan antara konsumen dan pegawai toko secara langsung (Baker dan Bitner dalam Eroglu et al., 2001), namun rangsangan yang diberikan oleh toko online (misalnya : warna, grafis, tata letak, dan desain) dapat memberikan informasi mengenai retailer tersebut (misalnya : kualitas atau jenis dari retailer, dan target konsumen) serta mempengaruhi tanggapan konsumen selama kunjungan ke situs tersebut (Chang dan Chen, 2008; Vrechopoulos, 2010). 


\section{Sany Surya \\ Dudi Anandya \\ Christina Rahardja Honantha}

H2: Atmosfer dari suatu website memliki hubungan positif terhadap emotional arousal konsumen online shop.

Hong, Tong, dan Tam (2004) dalam Wan et al., (2013) menyatakan bahwa desain dari website memberikan peran penting untuk mempengaruhi sikap konsumen terhadap suatu website, dimana saat desain layout suatu website lebih kondusif untuk digunakan, maka akan menghasilkan sikap positif dari pengguna website tersebut dan dapat meningkatkan kesediaan untuk mengunjungi kembali website tersebut.

H3: Desain layout dari suatu website memiliki hubungan positif terhadap sikap dari konsumen online shop

Berdasarkan model dari ELM disarankan bagi toko online dengan konteks yang tidak pasti untuk mendorong konsumennya untuk melakukan evaluasi dengan desain layout dan atmosfer (Vrechopoulos et al., 2004; Erogu et al., 2001).

H4: Atmosphere dari suatu website memiliki hubungan positif terhadap emotional arousal konsumen online shop

Kesenangan juga mempengaruhi tingkat kepuasaan konsumen, serta dapat mempengaruhi loyalitas konsumen terhadap suatu toko online dan jumlah pembelian yang dilakukan oleh konsumen tersebut (Mummalaneni, 2005)

H5 : Emotional arousal terhadap suatu website memiliki hubungan positif signifikan terhadap attitude toward the website.

Konsumen yang mempunyai pengalaman yang baik terhadap suatu toko (misalnya:display yang menarik) akan memiliki minat beli yang lebih besar dibandingkan dengan konsumen yang memiliki pengalaman yang buruk (Swinyard, 1993)

H6: Emotional arousal terhadap suatu website memiliki hubungan positif signifikan terhadap minat beli konsumen.

Wan et al., (2013) pada saat konsumen merasa yakin bahwa website yang dikunjungi memberikan manfaat yang dibutuhkan maka kemungkinan konsumen tersebut untuk melakukan pembelian akan lebih besar.

H7 : Sikap terhadap suatu website memiliki hubungan positif signifikan terhadap minat beli konsumen.

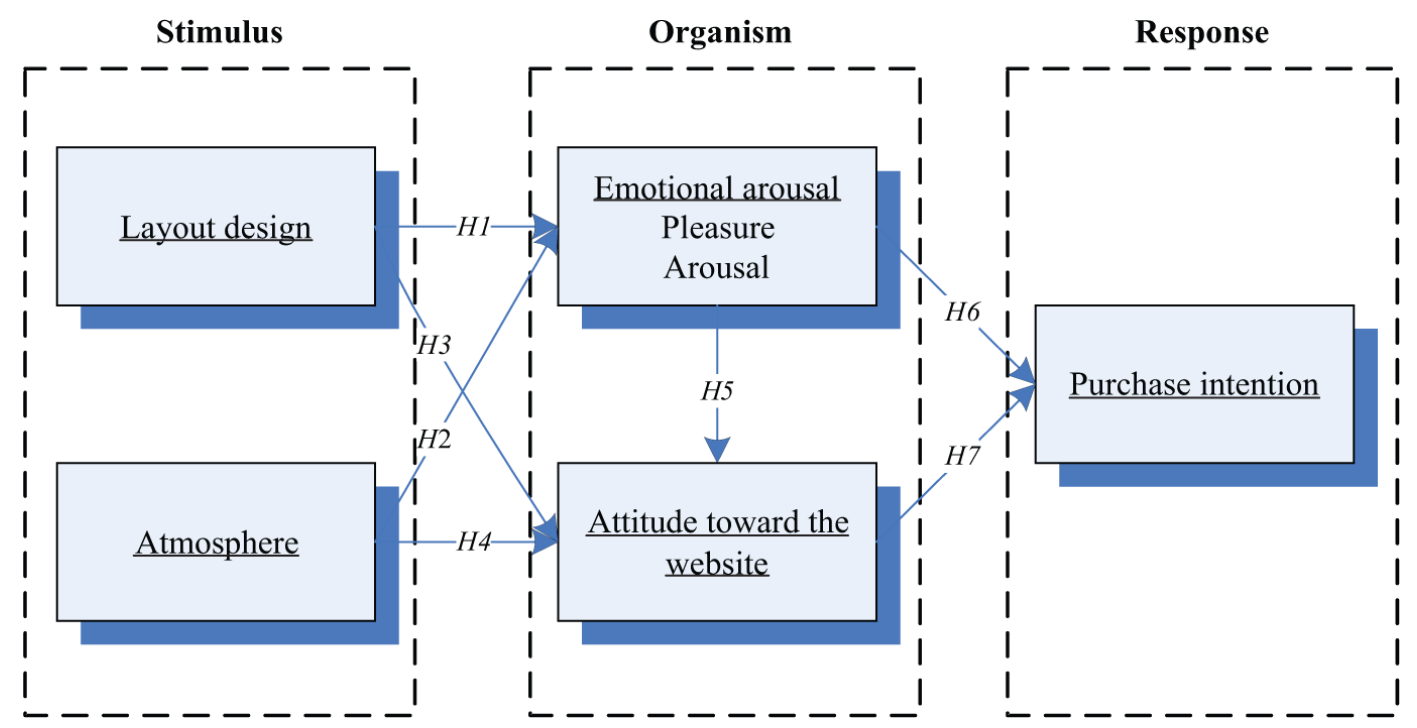

Gambar 1. Model Penelitian

Sumber : Wann et al., 2013 


\section{METODE PENELITIAN}

Jenis penelitian ini merupakan penelitian kausal. Pendekatan penelitian ini adalah kuantitatif karena menggunakan pengolahan data yang menghasilkan angka. Berdasarkan teknik, penelitian ini menggunakan survei karena mengumpulkan data dengan menanyakan langsung kepada responden melalui kuesioner. Aras pengukuran dalam penelitian ini menggunakan aras interval. Terdapat dua skala yang digunakan yaitu pertama, bipolar scale dengan aras interval. Bipolar scale yang digunakan adalah semantic differential scale (skala sikap) yang merupakan skala berpasangan. Responden memberikan penilaian terhadap pernyataan-pernyataan yang ada dan diukur dalam skala 7 poin jenjang seperti contoh sebagai berikut :

$\begin{array}{lllllllll}\text { Tidak teratur } & 1 & 2 & 3 & 4 & 5 & 6 & 7 & \text { Teratur }\end{array}$

Skala kedua adalah likert scale yang dilakukan dengan cara memberikan penilaian kepada serangkaian pertanyaan berdasarkan kata sifat dapat diukur dalam 7 skala jenjang, seperti contoh sebagai berikut :

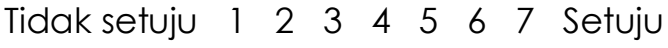

Target populasi dalam penelitian ini adalah pelanggan yang pernah mengunjungi dan membeli minimal 2 kali dalam 6 bulan, penggunaan internet minimal 2 jam per hari, pengeluaran untuk konsumsi di Zalora perbulan minimal sebesar Rp 300.000, memiliki pendidikan terakhir minimal SMA atau sederajat, dan usia minimal 17 tahun dengan pertimbangan memahami dan mengisi kuesioner dengan baik.

Teknik pengambilan sampel yang digunakan dalam penelitian ini adalah non probability sampling, yaitu teknik sampling yang memberikan peluang yang sama bagi setiap anggota populasi yang dipilih untuk menjadi sampel dan responden yang dipilih harus mempunyai kemampuan untuk memahami kuesioner yang diberikan. Jenis non probability sampling yang digunakan adalah convenience sampling yaitu teknik pengambilan sampel dengan menentukan elemen- elemen termudah saja dan pemilihannya tergantung pada peneliti sehingga peneliti bebas menetukan elemen yang dianggap paling mudah (Anandya dan Suprihhadi 2005, p199)

Pengolahan data dalam penelitian ini menggunakan Structural Equation Modeling (SEM). Menurut Hair, et al (1998) dalam Ferdinand (2002) Ukuran sampel adalah minimum 100 sedangkan maksimal tidak lebih dari 400. Perhitungan jumlah responden sendiri dapat dilakukan dengan cara mengkalikan minimal 5 dan maksimal 10 dengan jumlah total indikator yang diteliti. Penelitian ini menggunakan sampel sebesar 150 responden.

\section{HASIL PENELITIAN}

Berdasarkan data yang telah diperoleh dari hasil penyebaran kuesioner, dapat diperoleh informasi bahwa variabel layout design dipersepsikan baik oleh responden karena memiliki rata-rata 5,375 yang menunjukkan responden menyukai layout design Zalora online store. Rata- rata untuk variabel atmosphere 5,188 yang menunjukkan responden menyukai warna website Zalora online store. Rata- rata untuk variabel emotional arousal yang ditunjukkan oleh variabel pleasure 5,193 dan yang ditunjukkan oleh variabel arousal 5,148 yang menunjukkan responden senang dan tertarik membeli di Zalora online store. Rata- rata untuk variabel attitude toward the website 5,248 yang menunjukkan responden memiliki sikap positif terhadap website Zalora online store. Rata- rata untuk variabel purchase intention 5,265 yang menunjukkan responden berminat membeli di Zalora online store. 


\section{Sany Surya \\ Dudi Anandya \\ Christina Rahardja Honantha}

Tabel 1

Hasil Uji Kecocokan Model Pengukuran

\begin{tabular}{|c|c|c|c|c|}
\hline No & Uji Kecocokan & Kriteria Kecocokan & Hasil & Keterangan \\
\hline 1 & Chi-Square Statistic & $\begin{array}{l}\text { Diharapkan kecil, } \\
\mathrm{P} \geq 0,05\end{array}$ & $\begin{array}{c}453,75 \\
\mathrm{P}=0,00\end{array}$ & Not fit \\
\hline 2 & $\mathrm{RMSEA}$ & $\mathrm{RMSEA} \leq 0,08$ & 0,055 & Good fit \\
\hline 3 & $\mathrm{GFI}$ & $\mathrm{GFI} \geq 0,90$ & 0,82 & Marginal fit \\
\hline 5 & $\mathrm{TLI} / \mathrm{NNFI}$ & $\mathrm{TLI} \geq 0,90$ & 0,99 & Good fit \\
\hline 6 & $\mathrm{CFI}$ & $\mathrm{CFI} \geq 0,90$ & 0,99 & Good fit \\
\hline 7 & $\mathrm{CMIN} / \mathrm{DF}$ & $\mathrm{CMIN} / \mathrm{DF} \leq 2$ & 1,455 & Good fit \\
\hline
\end{tabular}

Sumber : Hasil Pengolahan Lisrel 8.70, diolah

Gambar 2

Measurement Model

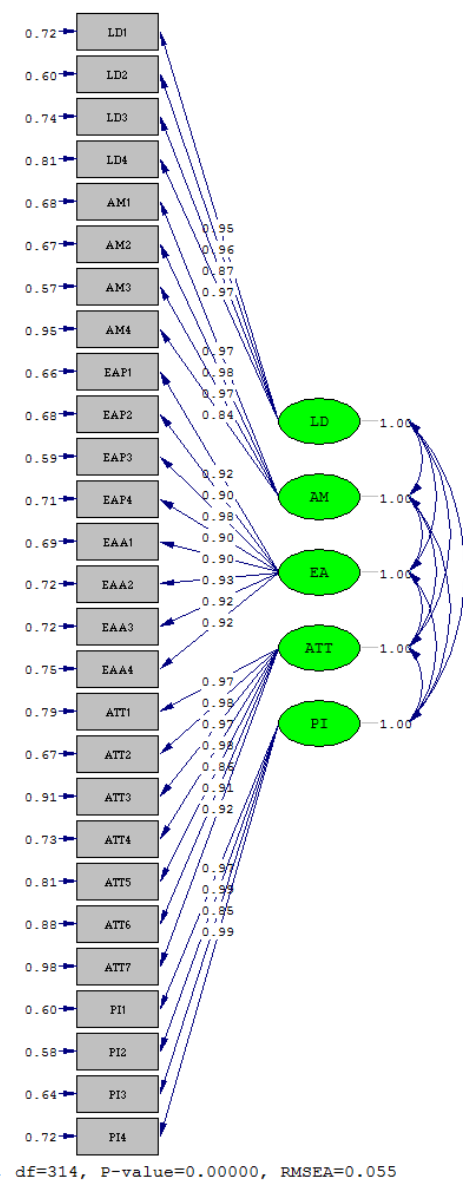

Sumber : Lisrel 8.70

Tabel 2

Composite Reliability

\begin{tabular}{|c|c|c|c|c|}
\hline Variabel & 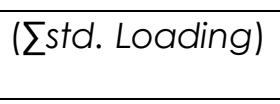 & $\left(\sum \text { std. Loading }\right)^{2}$ & Eerror & $\begin{array}{c}\text { Composite } \\
\text { Reliability }\end{array}$ \\
\hline LD & 3,66 & 13,395 & 2,91 & 0,82153 \\
\hline AM & 3,7 & 13,69 & 2,96 & 0,8222 \\
\hline EA & 7,36 & 54,1696 & 5,45 & 0,9085 \\
\hline ATT & 6,59 & 43,4281 & 5,05 & 0,8828 \\
\hline $\mathrm{Pl}$ & 3,8 & 14,44 & 2,53 & 0,850 \\
\hline
\end{tabular}

Sumber : Excel 2007, data diolah

Nilai std loading (standarized loading) dapat diperoleh secara langsung dari keluaran program Lisrel 8.70, sedangkan nilai error untuk setiap indikator, nilai ini juga diperoleh dari 
keluaran program Lisrel 8.70. Berdasarkan hasil pengujian yang telah dilakukan, semua variabel memiliki nilai lebih besar daripada 0,7 sehingga variabel yang digunakan secara umum sudah reliabel.

Tabel 3

Variance Extracted

\begin{tabular}{|c|c|c|c|c|}
\hline Variabel & ( $($ std. Loading) & ¿std. Loading 2 & Eerror & $\begin{array}{l}\text { Variance } \\
\text { Extracted }\end{array}$ \\
\hline LD & 3,66 & 3,3554 & 2,91 & 0,5355 \\
\hline AM & 3,7 & 3,4284 & 2,96 & 0,5366 \\
\hline EA & 7,36 & 6,7768 & 5,45 & 0,5542 \\
\hline ATT & 6,59 & 6,2167 & 5,05 & 0,5190 \\
\hline $\mathrm{PI}$ & 3,8 & 3,6236 & 2,53 & 0,588 \\
\hline
\end{tabular}

Sumber : Excel 2007, data diolah

Nilai std loading (standarized loading) dapat diperoleh secara langsung dari keluaran program Lisrel 8.70, sedangkan nilai error untuk setiap indikator, nilai ini juga duperoleh dari keluaran program Lisrel 8.70. Berdasarkan hasil pengujian yang telah dilakukan, semua variabel memiliki nilai lebih besar daripada 0,5 sehingga variabel yang digunakan secara umum sudah valid.

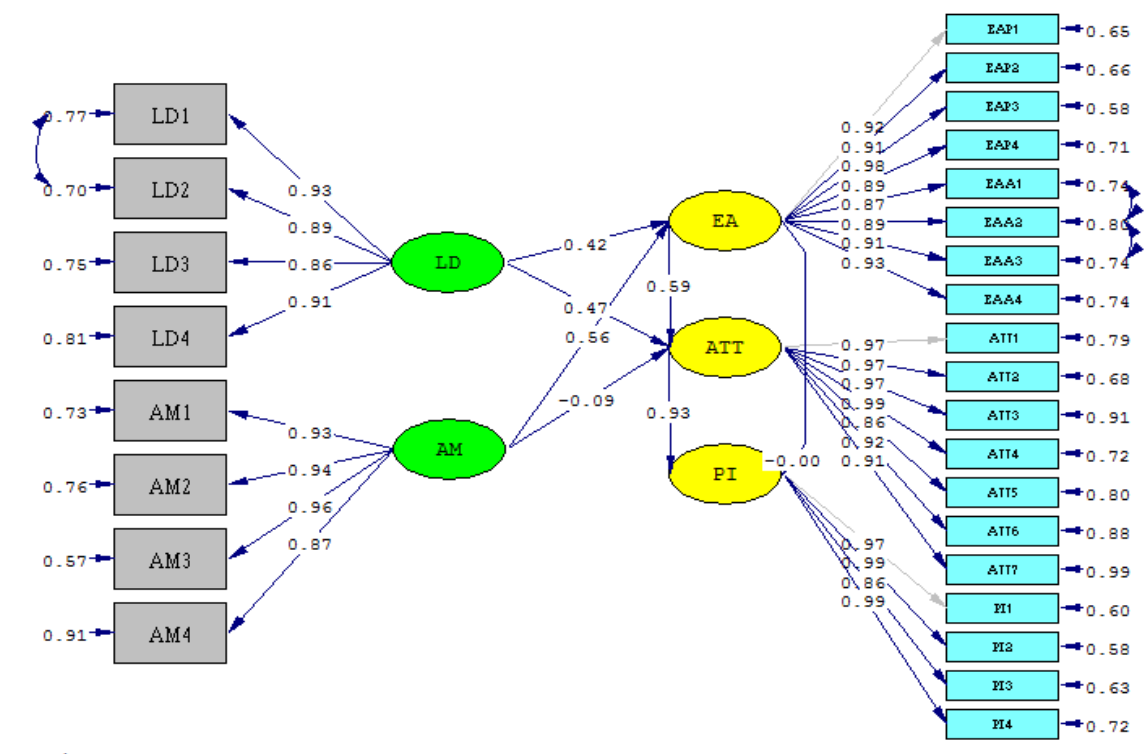

Chi-Square $=410.35, \mathrm{df}=313, \mathrm{P}-$ value $=0.00018, \mathrm{RMSEA}=0.046$

Gambar 3

Structural model setelah modifikasi

Sumber : Lisrel 8.70

Statistik chi-square digunakan untuk menguji kecocokan antara model dengan sampel. Nilai chi-square dari hasil uji kecocokan model menunjukkan hasil yang kurang baik, yang berarti model tidak cocok terhadap sampel yang digunakan. Nilai RMSEA dari hasil uji kecocokan model menunjukkan nilai yang baik, yang berarti tingkat error model apabila diestimasi dalam populasi cukup rendah. Nilai GFI dari hasil uji kecocokan model menunjukkan hasil yang cukup baik sebesar 0,83, berarti model tersebut kurang dapat menerangkan keragaman data. 


\section{Sany Surya \\ Dudi Anandya \\ Christina Rahardja Honantha}

\section{Tabel 4}

Hasil Uji Kecocokan Model Struktural Setelah Modifikasi Model Index

\begin{tabular}{|c|c|c|c|c|}
\hline No & Uji Kecocokan & Kriteria Kecocokan & Hasil & Keterangan \\
\hline 1 & Chi-Square Statistic & $\begin{array}{l}\text { Diharapkan kecil, } \\
\mathrm{p} \geq 0,05\end{array}$ & $\begin{array}{c}410,35 \\
\mathrm{P}=0,00018\end{array}$ & Not fit \\
\hline 2 & $\mathrm{RMSEA}$ & $\mathrm{RMSEA} \leq 0,08$ & 0,052 & Good fit \\
\hline 3 & $\mathrm{GFI}$ & $\mathrm{GFI} \geq 0,90$ & 0,83 & Marginal fit \\
\hline 4 & $\mathrm{AGFI}$ & $\mathrm{AGFI} \geq 0,90$ & 0,80 & Marginal fit \\
\hline 5 & $\mathrm{TLI} / \mathrm{NNFI}$ & $\mathrm{TLI} \geq 0,90$ & 0,99 & Good fit \\
\hline 6 & $\mathrm{CFI}$ & $\mathrm{CFI} \geq 0,90$ & 0,99 & Good fit \\
\hline 7 & $\mathrm{CMIN} / \mathrm{DF}$ & $\mathrm{CMIN} / \mathrm{DF} \leq 2$ & 1,31022 & Good fit \\
\hline 8 & $\mathrm{NFI}$ & $\mathrm{NFI} \geq 0,90$ & 0,97 & Good fit \\
\hline 9 & $\mathrm{IFI}$ & $\mathrm{IFI} \geq 0,90$ & 0,99 & Good fit \\
\hline 10 & $\mathrm{RFI}$ & $\mathrm{RFI} \geq 0,90$ & 0,96 & Good fit \\
\hline
\end{tabular}

Sumber : Hasil Pengolahan Lisrel 8.70, diolah

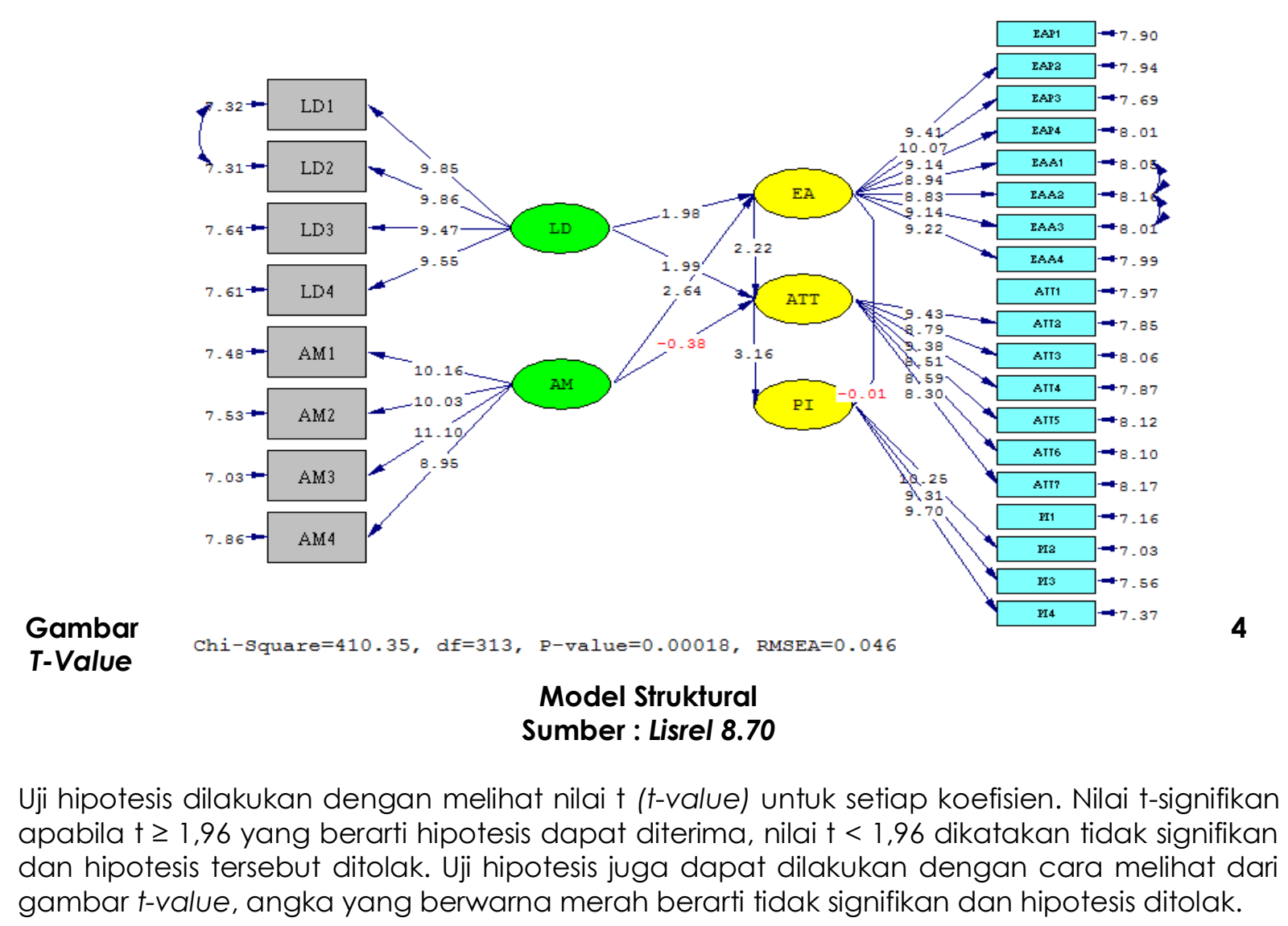


Tabel 5

Evaluasi terhadap Besarnya Pengaruh dan Kaitannya dengan Hipotesis Penelitian

\begin{tabular}{|c|c|c|c|l|}
\hline Hipotesis & Path & t-value & estimates & \multicolumn{1}{|c|}{ Keterangan } \\
\hline H1 & LD - EA & 1,98 & 0,42 & Hipotesis diterima \\
\hline H2 & AM - EA & 2,64 & 0,56 & Hipotesis diterima \\
\hline H3 & LD - ATT & 1,99 & 0,47 & Hipotesis diterima \\
\hline H4 & AM - ATT & $-0,38$ & $-0,09$ & Hipotesis ditolak \\
\hline H5 & EA - ATT & 2,22 & 0,59 & Hipotesis diterima \\
\hline H6 & EA - PI & $-0,01$ & $-0,00$ & Hipotesis ditolak \\
\hline H7 & ATT - PI & 3,16 & 0,93 & Hipotesis diterima \\
\hline
\end{tabular}

\section{Sumber : Hasil pengolahan Lisrel 8.70 , data diolah}

Terdapat $t$-value $-0,21$ dan 0,03 yang berarti tidak signifikan karena nilai tersebut dibawah 1,96. Dengan kata lain H4 yaitu pengaruh atmosphere (AM) terhadap attitude toward the website (ATT) tidak signifikan atau hipotesis ditolak. H6 yaitu emotional arousal (EA) terhadap purchase intention (PI) tidak signifikan atau hipotesis ditolak.

Berdasarkan hasil uji kausalitas untuk hipotesis keempat diperoleh nilai t-value sebesar $-0,038$ yang menunjukkan bahwa atmosphere tidak mempengaruhi attititude toward the website Zalora online store. Menurut hasil kuesioner yang telah dibagikan, responden secara keseluruhan menyukai warna (atmosphere) website Zalora online store tetapi tidak menjamin responden mempunyai sikap positif terhadap website Zalora online store, seperti berlama- lama membuka website Zalora.

Penelitian Yoo Changjo, Park Jonghee, dan Macinis. Deborah J (1998) membuktikkan bahwa atmosphere tidak dapat berpengaruh secara langsung terhadap store attitude namun melalui variabel yaitu in-store emotions, yang merupakan suasana hati seseorang atau kondisi psikologis pada saat pembelian yang memiliki dampak pada produk yang dibeli atau perilaku pembelian yang dilakukan.

Berdasarkan hasil uji kausalitas untuk hipotesis keenam diperoleh nilai t-valve sebesar $-0,01$ yang menunjukkan bahwa emotional arousal tidak mempengaruhi purchase intention Zalora online store. Menurut hasil kuesioner yang telah dibagikan, responden merasa senang dan bergairah untuk melakukan pembelian di Zalora online store tetapi tidak mempengaruhi minat beli responden akan melakukan pembelian lagi di Zalora online store apabila membutuhkan barang dalam waktu dekat.

Hasil ini tidak sesuai dengan jurnal Wann et al., (2013) yang diacu karena adanya perbedaan dalam karakteristik online store di China dan di Indonesia, dimana saat ini retailer di China yang bergerak di bidang online store adalah retailer yang memiliki brand terkenal seperti Zara, Puma, Coach, Hugo Boss, Cherokee dan brand-brand terkenal lainnya (http://indo.wsj.com/posts/2013/10/28/peritel-barat-mulai-lirik-toko-online-cina/), sedangkan online store di Indonesia seperti Zalora menjual produk dengan brand yang tidak terkenal atau brand lokal seperti Amarta Nawa, Al Mustika, Arula, Giffa, Zalia, Zumara, dan masih banyak brand lain, sehingga dari perbedaan karakteristik ini terjadi perbedaan perilaku pembelian konsumen. Dimana konsumen di China cenderung melakukan pembelian dengan memperhatikan brand terkenal sedangkan di Indonesia yang diperhatikan adalah gambar produk dan referensi dari konsumen lain ( http://www.marketing.co.id/karakter-danperilaku-khas-konsumen-indonesia/)

\section{KESIMPULAN DAN REKOMENDASI Kesimpulan}

Penelitian ini terdapat dua hipotesis yang tidak terbukti, dan terdapat lima hipotesis yang diterima. Model yang telah ada menggambarkan hasil data yang ada di lapangan terbukti 


\section{Sany Surya \\ Dudi Anandya \\ Christina Rahardja Honantha}

dari hasil goodness of fit indexes yang menunjukkan bahwa tingkat kesesuaian model terhadap data dapat dikatakan baik. Terdapat beberapa rekomendasi yang diharapkan dapat berguna bagi pihak Manajemen Zalora online store dan untuk penelitian selanjutnya.

\section{Rekomendasi Bagi Zalora Online store}

1. Berdasarkan hasil penelitian, dapat dijelaskan variabel attitude toward the website memiliki pengaruh signifikan terhadap purchase intention, dan dari hasil t-value memiliki nilai sebesar 3,16 dan estimates sebesar 0,93, yang berarti Zalora perlu meningkatkan kualitas dari desain website, dengan cara menata waktu dan tampilan pop-up message atau pesan yang sering muncul baik dari website Zalora sendiri atau dari website lain yang terkadang selalu muncul saat ada promosi baru yang ditawarkan, karena pop-up message tersebut terkadang menganggu pencarian barang yang dilakukan oleh konsumen.

2. Berdasarkan hasil penelitian, dapat dijelaskan variabel layout design memiliki pengaruh signifikan terhadap kesenangan dan sikap konsumen dari suatu website, dimana Zalora dapat menambahkan informasi mengenai produk yang dijual seperti ukuran dan warna yang tersedia untuk produk yang ditawarkan, serta stock dari produk tersebut sehingga konsumen dapat mengetahui informasi lebih mendetail terkait produk yang akan dibeli. Tidak tersedianya tampilan stock, mengakibatkan Zalora sering membatalkan secara sepihak produk yang dibeli oleh konsumen dengan alasan barang tersebut sudah habis ataupun belum tersedia, sehingga disini pihak Zalora seharusnya mampu memperbaiki sistem ketersediaan barangnya agar tidak terjadi pemutusan sepihak yang dapat merugikan konsumen (http://www.kaskus.co.id/thread/50fbf62b7d1243292c000004/belanja-di-zaloracoidpikir-dulu-1000-kali-pict-inside)

\section{Rekomendasi Bagi Penelitian Selanjutnya}

1. Penelitian ini hanya dilakukan pada fashion online store. Penelitian selanjutnya dapat menggunakan berbagai online store lain yang juga menjual barang kebutuhan sehari- hari maupun elektronik sehingga mendapatkan hasil penelitian yang lebih baik.

2. Penelitian ini hanya dilakukan pada satu website saja tanpa membandingkan website lain. Penelitian selanjutnya dapat membandingkan beberapa online store yang memiliki perbedaan karakteristik sekaligus untuk mengetahui perbedaan minat beli dalam online store yang memiliki karakteristik berbeda.

\section{DAFTAR REFERENSI}

Anandya, Dudi dan Heru Suprihhadi, 2005 Riset Pemasaran Prospektif \& Terapan.

Cyr, D., Milena, H, and Hector, L. 2009. Colour Appeal in website design within and accross cultures: A multi-method evaluation. Int. J-Human Computer Studies, 68 (2010) 1-21.

Drolet, A and Jennifer, A. 2002. Off-Target? Changing Cognitive-Based Attitudes. Journal of Consumer Psychology, 12(1), 59-68.

Eroglu, A. S., Karen, A. M., and Lenita, M. D. 2001. Atmospherics qualities of online retailing: A conceptual model and implications. Journal of Business Research, 54 (2001) 177-184.

Farley, D. S and Mark, F. S. 2003. Relative Influences of Affect and Cogniton on Behavior: Are Feelings or Beliefs More Related to Blood Donation Intentions? Experimental Psychology 2003, Vol. 50(1): 55-62.

Ferdinand dan, Augusty, 2002, Structural Equation Modeling Dalam Penelitian Manajemen Aplikasi Model-Model Rumit Dalam Penelitian Untuk Tesis Magister dan Disentasi Doktor, Fakultas Ekonomi UNDIP, Semarang.

Kraft, P., Jostein, R., Stephen, S., and Espen, R, 2005, Perceived difficulty in the theory of planned behavior: Perceived behavioural control or affective attitude. British Journal og Social Psychology, (2005), 44, 479-496.

Leon G. S and Leslie, L, K, 2008, Consumer Behavior, Seventh Edition. 
Levy and Weithz, 2009, Retailing management, MCCraw Hill: Bolton.

Manganari, E, E., George, J, S and Adam, P, V, 2010, Store Atmosphere in web retailing. European Journal of Marketing, Vol. 43 No9/10, 2009 pp.1140-1153.

Manganari, E, E., George, J, S, Irini, D, R and Adam, P, V. 2011, Virtual store layout effects on consumer behavior: Applying an environmental psychology approch in the online travel industry. Internet Research, Vol.21 No.3, 2011 pp. 326-346.

Martinez-Lopez, F, J., Luna, P and Martinez, F, J. 2005. Online shopping, the standart learning hierarcy and consumers' internet expertise: an American- Spanish comparison. Ineternet Research, Vol. 15 No. 3, pp. 312-334.

Mummalaneni, V. 2005. An empirical investigation of Web site characteristics, consumer emotional states and on-line shooping behaviors. Journal of Business Reaserch, 58 (2005) 526-532.

Wann, Y, W., Chia, L, L., Chen, S F, and Hong, C, W. 2014. How can online store layout design and atmosphere influence consumer shopping intention on a website? International Journal of Retail \& Distribution Management., Vol. 42 Nol, 2014 pp. 4-24.

Yoo, C., Jonghee, P, and Deborah J, M. 1998. Effects of Store Characteristics and In-store Emotional Experiences on Store Attitude. Journal of Business Research, 42, 253263(1998).

http://harianti.com/survei-bps-jumlah-pengguna-internet-indonesia-tahun-2013-tembus-71-

juta-orang/

http://economy.okezone.com/read/2013/04/01/320/784483/redirect/large

http://startupbisnis.com/hadi-wenas-membagikan-rahasia-sukses-zalora-the-biggest-fashion-

ecommerce-dengan-satu-juta-order/

http://danudion.mhs.narotama.ac.id/

http://www.merdeka.com/teknologi/9-e-commerce-yang-sedang-berjaya-di-indonesia.html

http://swa.co.id/business-strategy/management/cara-zalora-berkembang-menjadi-e-

commerce-terbesar-di-asia-tenggara

http://www.marketing.co.id/karakter-dan-perilaku-khas-konsumen-indonesia/

http://www.kabar24.com/gaya-hidup/read/201404402/81/214954/survei-google-inilah-

perilaku-pembeli-online-di-indonesia

http://www.chinadaily.com.cn/bizchina/2013-08/22/content 16912758.htm

http://indo.wsj.com/post/2013/10/28/peritel-barat-mulai-lirik-toko-online-cina/ 